\title{
Defining Glyphosate and Dicamba Drift Injury to Dry Edible Pea, Dry Edible Bean, and Potato
}

\author{
Harlene Hatterman-Valenti ${ }^{1,4}$, Greg Endres ${ }^{2}$, Brian Jenks ${ }^{3}$, \\ Michael Ostlie $^{2}$, Theresa Reinhardt ${ }^{1}$, Andrew Robinson ${ }^{1}$, \\ John Stenger ${ }^{1}$, and Richard Zollinger ${ }^{1}$
}

\begin{abstract}
AdDitional Index wORDs. Pisum sativum, Phaseolus vulgaris, Solanum tuberosum, herbicide, off-target

SUMMARY. Field trials using sublethal doses of glyphosate, dicamba, or mixtures of both herbicides on dry edible pea (Pisum sativum), dry edible bean (Phaseolus vulgaris), and potato (Solanum tuberosum) were conducted at six locations to determine the injury potential if spray drift were to occur. All studies used three increasing sublethal doses of glyphosate and dicamba, which were labeled as low, medium, and high. The doses for each herbicide varied for the three crops because of expected sensitivity differences. Herbicide doses were targeted for the reproductive stage 1 with dry edible pea and dry edible bean, and at tuber initiation for potato. Visible injury 20 days after the treatment ranged from $0 \%$ to $13 \%$ for dry edible pea, $0 \%$ to $53 \%$ for dry edible bean, and $0 \%$ to $50 \%$ for potato.

Compared with the nontreated, yield was least when doses included dicamba, regardless of the crop. Dry edible bean was the most sensitive crop to sublethal doses of dicamba, followed by dry edible pea and potato. Results from these six studies suggested that drift injury potential to dry edible pea, dry edible bean, and potato will be greater if a dicamba-resistant soybean (Glycine max) crop is adjacent and upwind compared with a glyphosate-resistant crop. Results also reinforce the need for diligence in the application of these herbicides in proximity to susceptible crops and the need to thoroughly clean sprayers before spraying a sensitive crop.
\end{abstract}

$\mathrm{D}$ icamba is commonly used as a postemergence herbicide in corn (Zea mays), small grains, and pastures. Recent advances have led to the development of dicambaresistant soybean and cotton (Gossypium hirsutum) cultivars to combat glyphosate-resistant weedy species. Herbicide drift has been and continues to be a problem across agriculture production areas. Off-target spray drift can lead to economic losses and legal disputes among producers and applicators. In the past, the primary herbicide of concern was glyphosate because of its large-scale use enabled by its relationship with highly adopted glyphosate-resistant crop cultivars. Increased intermixing of glyphosate-resistant crops and

\footnotetext{
${ }^{1}$ Department of Plant Sciences, North Dakota State University, P.O. Box 6050, Dept. 7670, Fargo, ND 58108

${ }^{2}$ North Dakota State University Carrington Research Extension Center, 663 Hwy. 281 N., Carrington, ND 58421

${ }^{3}$ North Dakota State University North Central Research Extension Center, 5400 Highway 83 S., Minot, ND 58701

${ }^{4}$ Corresponding author. E-mail: h.hatterman.valenti@
} ndsu.edu.

doi: 10.21273/HORTTECH03679-17 horticultural crops has occurred in North Dakota as glyphosate-resistant soybean acres in the state continue to rise (Fig. 1). Similarly, there are 385,000 acres of dry edible pea, 655,000 acres of dry edible bean, and 82,000 acres of potato production, respectively, with a total production value at nearly $\$ 537$ million annually (USDA, 2017). With the recent release of stacked glyphosateand dicamba-resistant soybean cultivar options, as well as the pending licensing of glyphosate and dicamba herbicide mixtures, concerns exist regarding increases in off-target injury to broadleaf and horticultural crops (Johnson et al., 2012). Several studies have reported injury from simulated glyphosate drift on specialty crops such as onion [Allium cepa (Felix et al., 2012)], potato (Felix et al., 2011; Hatterman-Valenti, 2014), and tomato [Solanum lycopersicum (Gilreath et al., 2001a; McNaughton et al., 2012)]. Several studies have also reported injury from simulated dicamba drift on specialty crops such as bell pepper [Capsicum annuum (Gilreath et al., 2001b; MohseniMoghadam and Doohan, 2015)], broccoli [Brassica oleracea var. italica (Mohseni-Moghadam and Doohan, 2015)], dry edible pea (Al-Khatib and Tamhane, 1999), potato (Colquhoun et al., 2014; Wall, 1994), snap bean [Phaseolus vulgaris (Colquhoun et al., 2014)], tomato (Kruger et al., 2012), and yellow squash [Cucumis melo (Dittmar et al., 2016)]. Dicamba is of particular concern because of its volatility when applied under high temperature conditions. The potential for off-label applications of diglycolamine (DGA) salts rather than registered formulations with reduced volatility also causes concern. Although companies and agencies address the volatility concerns of dicamba products to producers, increased damage due to particle drift or insufficient tank cleaning may also lead to economic losses and disputes. In addition, the combination of two modes of action may result in amplified effects when applied jointly. Many studies have investigated the effects of offtarget simulated drift of glyphosate or dicamba independently; however, their combined effects in drift simulations have not been well documented (Dittmar et al., 2016). The following research evaluated the relative effects of sublethal doses of glyphosate, dicamba, or the combination of the two herbicides to capture the potential yield reductions from off-target herbicide movement to dry edible

\begin{tabular}{llll}
\hline $\begin{array}{l}\text { Units } \\
\begin{array}{l}\text { To convert U.S. to SI, } \\
\text { multiply by }\end{array}\end{array}$ & U.S. unit & SI unit & $\begin{array}{l}\text { To convert SI to U.S., } \\
\text { multiply by }\end{array}$ \\
\hline 0.4047 & acre $(\mathrm{s})$ & $\mathrm{ha}$ & 2.4711 \\
112.0851 & $\mathrm{cwt} / \mathrm{acre}$ & $\mathrm{kg} \cdot \mathrm{ha}^{-1}$ & 0.0089 \\
9.3540 & gal/acre & $\mathrm{L} \cdot \mathrm{ch}^{-1}$ & 0.1069 \\
2.54 & inch $(\mathrm{es})$ & $\mathrm{cm}$ & 0.3937 \\
1.1209 & $\mathrm{lb} / \mathrm{acre}$ & $\mathrm{kg} \cdot \mathrm{ha}^{-1}$ & 0.8922 \\
28.3495 & $\mathrm{oz}$ & $\mathrm{g}$ & 0.0353 \\
70.0532 & $\mathrm{oz} / \mathrm{acre}$ & $\mathrm{g} \cdot \mathrm{ha}^{-1}$ & 0.0143 \\
6.8948 & $\mathrm{psi}$ & $\mathrm{kPa}$ & 0.1450 \\
$\left({ }^{\circ} \mathrm{F}-32\right) \div 1.8$ & ${ }^{\circ} \mathrm{F}$ & ${ }^{\circ} \mathrm{C}$ & $\left({ }^{\circ} \mathrm{C} \times 1.8\right)+32$
\end{tabular}




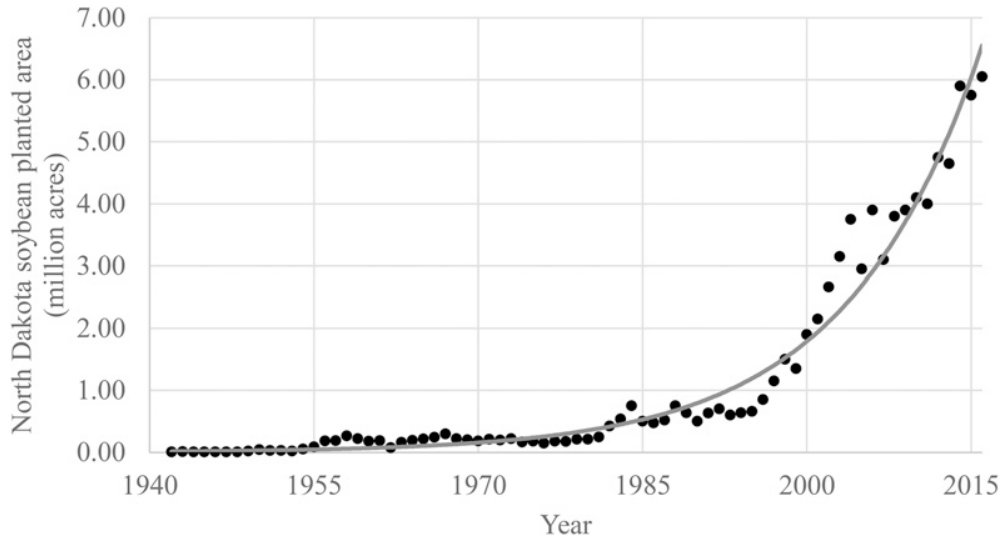

Fig. 1. North Dakota soybean planted area. Data obtained from the U.S. Department of Agriculture database (USDA, 2017) on 27 Jan. 2017; 1 acre $=0.4047$ ha.

bean, dry edible pea, and potato, three nonherbicide-resistant crops prevalent in the region.

\section{Materials and methods}

Field management. Three crop species were independently evaluated at two locations for the effects of simulated off-target drift of glyphosate, dicamba, or the combination of these two herbicides. 'Blue Moon', a green cotyledon type dry edible pea widely grown in North Dakota, was planted into a loam soil at the North Dakota State University (NDSU) North Central Research and Extension Center (lat. $48^{\circ} 10^{\prime} 54.2^{\prime \prime} \mathrm{N}$, long. $101^{\circ} 17^{\prime} 50.8^{\prime \prime} \mathrm{W}$ ) near Minot, ND, and a silty loam soil at the NDSU Carrington Research Extension Center (lat. 47 $30^{\prime} 29.3^{\prime \prime} \mathrm{N}$, long. $\left.99^{\circ} 07^{\prime} 14.9^{\prime \prime} \mathrm{W}\right)$ near Carrington, ND, on 4 May and 17 Apr. 2015, respectively. Crop rows were at a 7 -inch spacing and a target population of 300,000 seeds/acre. Field preparation, fertilizer, weed control, and pest management practices followed recommendations from the NDSU Extension Dry Edible Pea Production Guide (Endres et al., 2016). A preliminary trial was conducted in 2014 to determine sublethal herbicide doses. Herbicide application timing was targeted at the preflower stage and applied postemergence at Minot and Carrington on 23 and 15 June, respectively, using a carbon dioxide $\left(\mathrm{CO}_{2}\right)$-backpack sprayer equipped with a hand-boom and four XR8001 nozzles (Spraying Systems Co., Wheaton, IL) delivering $9 \mathrm{gal} / \mathrm{acre}$ at $40 \mathrm{psi}$. Research has shown that stressing dry edible pea at the early flowering stage can greatly reduce the yield potential (Endres et al., 2016). Herbicide doses were applied to the middle plot rows so that the outer quarter of each plot would encounter any off-target herbicide and reduce/ eliminate spray drift to adjacent plots. Dry edible pea plots were harvested at Minot and Carrington on 10 Aug. and 30 July, respectively.

'Lariat' pinto bean ( $P$. vulgaris) was planted at Carrington, whereas 'Ensign' navy bean ( $P$. vulgaris) was planted into a silty clay loam soil at a location (lat. $47^{\circ} 45^{\prime} 07.7^{\prime \prime} \mathrm{N}$, long. $\left.97^{\circ} 05^{\prime} 23.6^{\prime \prime} \mathrm{W}\right)$ near Thompson, $\mathrm{ND}$, on 28 and 20 May 2015, respectively. Both cultivars are commonly grown for their specific market class in North Dakota. Crop rows were at a 30 -inch row spacing and a target population of 300,000 seeds/acre. Field preparation, fertilizer, weed control, and pest management practices followed recommendations from the NDSU Extension Dry Edible Bean Production Guide (Osorno et al., 2013). A preliminary trial the prior year at Thompson was used to determine herbicide doses for the current study. Sublethal herbicide treatments were applied postemergence to plants in the middle two rows of the four-row plots at the reproductive stage $\mathrm{l}(R \mathrm{l})$ at Carrington and Thompson on 20 and 23 July, using a $\mathrm{CO}_{2}$-backpack sprayer equipped with a hand-boom and either XR80As or TT11002 nozzles (both Spraying Systems Co.) delivering either 9 or $20 \mathrm{gal} / \mathrm{acre}$ at 40 psi, respectively. As with dry edible pea, stresses at the early flowering stage have been shown to cause the greatest yield reduction in dry edible bean (Osorno et al., 2013). Dry edible bean plots at Carrington were harvested on 24 Sept. through 20 Oct. because of delays in maturation associated with the herbicide treatments. Dry edible bean plots at Thompson were desiccated with paraquat (Gramoxone Inteon; Syngenta Crop Protection, Greensboro, NC) on 28 Sept. and harvested on 6 Oct.

The potato cultivar Russet Burbank was planted into a sandy loam soil at the NDSU Oakes Irrigation Research Site (lat. 46 $04^{\prime} 24.1^{\prime \prime} \mathrm{N}$, long. $\left.98^{\circ} 05^{\prime} 31.4^{\prime \prime} \mathrm{W}\right)$ near Oakes, $\mathrm{ND}$, and a loamy sand soil at the Northern Plains Potato Growers Association Irrigation site (lat. $48^{\circ} 10^{\prime} 09.8^{\prime \prime} \mathrm{N}$, long. $97^{\circ} 43^{\prime} 20.4^{\prime \prime} \mathrm{W}$ ) near Inkster, ND, on 22 May and 10 June 2015, respectively. 'Russet Burbank' has historically been the primary cultivar grown under irrigation in North Dakota. Seed pieces $(2 \mathrm{oz})$ were cut and suberized for $\approx \mathrm{l}$ week before planting. Crop rows were at a 36-inch row spacing with a 12 -inch spacing between seed pieces. Field preparation, fertilizer, weed control, and pest management practices were according to the recommendations from the NDSU/MN Extension Potato Production and Pest Management Guide (Bissonnette et al., 1993). Previous research examining simulated glyphosate drift to potato was used to determine herbicide doses and application timing for the current study (Hatterman-Valenti, 2012). Sublethal herbicide doses were applied to plants in the middle two rows of the four-row plots at the tuber initiation stage on 7 and 30 July for Oakes and Inkster, respectively, using a $\mathrm{CO}_{2}$-backpack sprayer equipped with a hand-boom and XRl1002 nozzles (Spraying Systems Co.) delivering $20 \mathrm{gal} / \mathrm{acre}$ at 40 psi. Plots were harvested 29 Sept. and 16 Oct. at Oakes and Inkster, respectively.

Sublethal Herbicide DOSEs. At each location, 10 experimental treatments comprised three sublethal doses of glyphosate and dicamba as well as combinations of both herbicides and were arranged in a randomized complete block design with three replicate blocks for the dry edible bean trials or four replicate blocks for the dry edible pea and 
potato trials. Sublethal herbicide doses were originally selected from preliminary studies using glyphosate, with the dicamba dose selected so that it represented the ratio for the proposed glyphosate plus dicamba label. The herbicide doses will be referred to as low, medium, and high for ease of discussion. The 10th treatment in each trial was not treated as no herbicide was applied.

In dry edible pea, glyphosate (Roundup PowerMax; Monsanto Co., St. Louis, MO) doses from low to high were $0.06,0.31$, and $0.6 \mathrm{oz} / \mathrm{acre}$, whereas dicamba (Clarity; BASF Corp., Research Triangle Park, NC) doses from low to high were $0.025,0.125$, and $0.25 \mathrm{oz} /$ acre. The middle dicamba dose used at Minot was slightly higher at $0.138 \mathrm{oz} /$ acre because of miscommunication between researchers. The combination doses from low to high would be $\approx 1 / 160,11 / 320$, and $3 / 80$, the proposed dicamba+glyphosate label-recommended rate for resistant soybean.

In dry edible bean, the two locations used different sublethal doses with the doses at Carrington almost three times those used at Thompson because of miscommunication between researchers. At Thompson, glyphosate doses from low to high were $0.005,0.05$, and $0.5 \mathrm{oz} / \mathrm{acre}$, whereas dicamba doses from low to high were $0.003,0.03$, and $0.25 \mathrm{oz} /$ acre. The combination doses from low to high would be $\approx 1 / 3200,1 / 320$, and $1 / 32$, the proposed dicamba+ glyphosate label-recommended rate for resistant soybean. At Carrington, glyphosate doses from low to high were $0.014,0.14$, and $1.4 \mathrm{oz} / \mathrm{acre}$, whereas dicamba doses from low to high were $0.007,0.07$, and $0.7 \mathrm{oz} / \mathrm{acre}$, with a 10 -fold difference between doses. The combination doses from low to high would be $\approx 7 / 8000,7 / 800$, and $7 / 80$, the proposed dicamba+glyphosate label-recommended rate for resistant soybean.

In potato, glyphosate doses from low to high were $0.1,0.56$, and $2.8 \mathrm{oz} /$ acre, whereas dicamba doses from low to high were $0.06,0.32$, and $1.4 \mathrm{oz} / \mathrm{acre}$, with the high dose at twice the dose used on dry edible bean at Carrington. The combination doses from low to high would be $\approx 1 / 160,3 / 80$, and $7 / 40$, the proposed dicamba+glyphosate label-recommended rate.
Evaluation. For each treated plot, a visible evaluation of injury symptomology was recorded $\approx 10$ and $20 \mathrm{~d}$ after treatment (DAT) using a scale of 0 to 100 where $0=$ no foliar injury symptoms and $100=$ plant death. Injury evaluation timings were selected to capture response symptoms for all three crops and both herbicides. On harvest, plot yield was also evaluated to infer the economic implications from known sublethal doses and visible injury symptomology. In addition, for the analysis of potato, the marketable yield was analyzed as harvest of unsalable tubers may cause an impactful difference in uncompensated harvest cost.

Data analysis. All analysis of variance (ANOVA) analyses were performed using the mixed procedure of SAS statistical software (version 9.4; SAS Institute, Cary, NC) using the type 3 method for estimating covariance parameters. In each test, rates of glyphosate, dicamba, or combinations of the rates were considered fixed, whereas replicates were treated as random effects. Type 3 estimation was used so the effect of the random replications would not be pooled with the experimental error allowing spatial gradients to be accounted for. Data from the two locations of each crop were evaluated separately because herbicide doses for the two dry edible bean locations differed, and a test of homogeneity of variance on dry edible pea and potato indicated the two potato locations could not be combined. After the confirmation of significant variation among treatments, mean separations were completed using pairwise $t$ tests at a confidence level of $95 \%$. Analysis of covariance (ANCOVA) was used to investigate relationships between percent visible injury 20 DAT and yield reduction using the following linear equation:

$$
\begin{aligned}
\text { yield }= & \operatorname{Rep}\left(B_{0}\right)+\operatorname{Hb}\left(B_{1}\right) \\
& +\left(\beta_{0}\right) 20 \text { DATinj } \\
& +\operatorname{Hb}^{*} 20 \text { DATinj }\left(B_{3}\right) .
\end{aligned}
$$

where Rep is the design matrix of replicates, $B_{0}$ is a matrix containing the estimated replicate main effects, $\mathrm{Hb}$ is the design matrix of herbicide treatments (glyphosate, dicamba, or glyphosate+dicamba), $B_{1}$ is a matrix containing the estimated herbicide treatment main effects, $\beta_{0}$ is the slope of the regression line relating visible injury 20 DAT to yield, 20DATinj is visible injury as a percentage recorded $20 \mathrm{DAT}, \mathrm{Hb}^{*} 20 \mathrm{DAT}$ inj is a matrix containing the treatment specific visible percentages, and $B_{3}$ is a matrix containing the specific slopes of each herbicide treatment. Analysis was carried out using the GLM procedure of SAS statistical software using the type 1 method for estimating covariance parameters and was evaluated at a confidence level of $95 \%$.

\section{Results}

Crop injury ratings varied little between evaluations at 10 and 20 DAT, thus discussion will focus on the 20 DAT evaluations and how those ratings related to yield reductions for each crop.

DRY EDIBLE PEA. In both trials, the lowest rate applied of either chemical or their combined application did not result in visible injury 20 DAT or yield reduction (Table 1). At Carrington, dry edible pea injury was $<15 \%$ for all treatments at 20 DAT. Increasing herbicide rates did lead to increasing visible symptomology, but yields were not reduced when compared with the nontreated. The most commonly observed crop response was an increase in tendril production when dicamba was applied (Fig. 2). Dry edible pea yield did not differ from the nontreated, which suggested that low amounts of particle drift $(\leq 3 / 80$ the label-recommended rate) from dicamba+glyphosate will not reduce dry edible pea yield.

However, at Minot, the middle and high doses of dicamba alone or with glyphosate caused increased dry edible pea injury 20 DAT (Table 1). These doses also reduced dry edible pea yield compared with the nontreated with the exception of the middle dicamba dose. A $16 \%$ yield reduction occurred with the high dose of dicamba, whereas a $35 \%$ yield reduction occurred with the high dose of dicamba+glyphosate compared with the nontreated. Unlike the results from Carrington, the results from Minot suggest that dicamba misapplied or drifted may cause a yield reduction in dry edible pea, and the combined application of dicamba and glyphosate misapplied or drifted may further reduce yield when compared 
Table 1. Impact of sublethal doses of dicamba, glyphosate, or dicamba + glyphosate on dry edible pea foliar injury $20 \mathrm{~d}$ after treatment (DAT) and yield.

\begin{tabular}{|c|c|c|c|c|c|}
\hline \multicolumn{2}{|c|}{ Herbicide dose } & \multicolumn{2}{|c|}{ Carrington, ND } & \multicolumn{2}{|c|}{ Minot, ND } \\
\hline Dicamba (lb/acre) $)^{z}$ & Glyphosate (lb/acre) & Injury 20 DAT (\%) & Yield (lb/acre) & Injury 20 DAT (\%) & Yield (lb/acre) \\
\hline 0 & 0 & $0 \mathrm{a}^{\mathrm{y}}$ & $1,448 \mathrm{a}$ & $0 \mathrm{a}$ & $1,713 \mathrm{a}$ \\
\hline 0.008 & 0 & $3 a b$ & $1,473 \mathrm{a}$ & $4 \mathrm{~b}$ & $1,545 \mathrm{ab}$ \\
\hline 0.016 & 0 & $8 \mathrm{c}$ & $1,490 \mathrm{a}$ & $6 \mathrm{c}$ & 1,435 bc \\
\hline 0 & 0.004 & $3 a b$ & $1,483 \mathrm{a}$ & $0 \mathrm{a}$ & $1,613 \mathrm{ab}$ \\
\hline 0.002 & 0.004 & $0 \mathrm{a}$ & $1,553 \mathrm{a}$ & $1 \mathrm{a}$ & $1,758 \mathrm{a}$ \\
\hline 0.008 & 0.02 & $4 \mathrm{~b}$ & $1,478 \mathrm{a}$ & $7 \mathrm{~d}$ & $1,283 \mathrm{~cd}$ \\
\hline 0.016 & 0.04 & $13 \mathrm{~d}$ & $1,175 \mathrm{a}$ & $11 \mathrm{e}$ & $1,110 \mathrm{~d}$ \\
\hline
\end{tabular}

${ }^{\mathrm{z}} 1 \mathrm{lb} / \mathrm{acre}=1.1209 \mathrm{~kg} \cdot \mathrm{ha}^{-1}$.

${ }^{y}$ Within columns, mean followed by the same letter do not differ according to pairwise $t$ tests at $P \leq 0.05$.

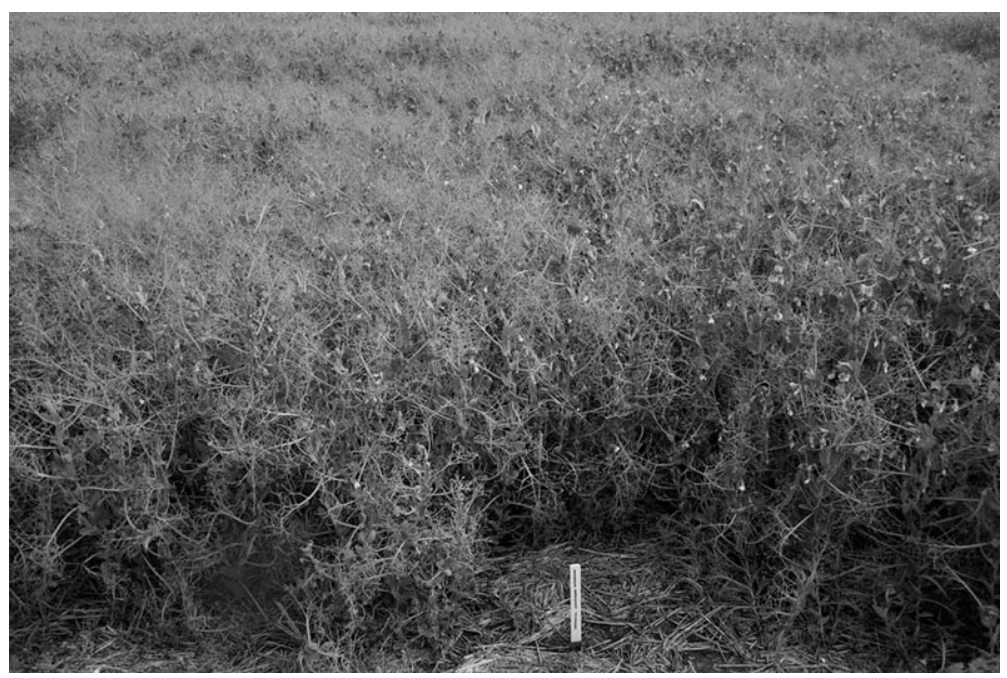

Fig. 2. Dry edible pea visible injury (5\%) $20 \mathrm{~d}$ after treatment from dicamba applied at $0.016 \mathrm{lb} /$ acre $\left(0.0179 \mathrm{~kg} \cdot \mathrm{ha}^{-1}\right)$ on the left and a nontreated dry edible pea plot on the right with normal tendril production.

with damage occurring from dicamba alone. Overall, dicamba tended to show greater injury to dry edible pea than glyphosate at the doses used in the current study.

Decline in yield was associated with increased observed injury 20 DAT at both locations. In Minot, yield was reduced by $131.8 \mathrm{lb} /$ acre for each percent of observed injury regardless of herbicide or herbicide combination applied $(P<0.01)$. In Carrington, specific herbicides and herbicide combinations had different relationships between visible injury and yield $(P<0.01)$ resulting in differing yield trends (dicamba, 2.0; glyphosate, -14.0 ; dicamba+glyphosate, $-35.5 \mathrm{lb} /$ acre).

DRY eDIBLe beAN. At Carrington, where higher doses were used, more damage (necrosis of growing points, petiole epinasty, leaf cupping, and leaf margin necrosis) was observed on plants compared with those at Thompson (Fig. 3; Table $2)$. At Carrington, visible symptomology of the medium and high doses of each herbicide alone and all doses in combination caused distinguishable injury compared with the nontreated at 20 DAT. Of these, only the low dose of dicamba+glyphosate and the middle dose of glyphosate caused less than $20 \%$ crop injury, yet the yield differences between the two treatments was almost 3 -fold with greater yield reduction from the medium dose of glyphosate. The medium and high dicamba doses reduced the dry edible bean yield to zero, whereas the medium and high glyphosate doses reduced the yields by $70 \%$ and $64 \%$, respectively, compared with the nontreated, even though no plants were killed by the sublethal herbicide doses. Results suggested that dicamba alone from as little as $7 / 800$ of the proposed dicamba+glyphosate labelrecommended rate for resistant soybean onto dry edible bean at the $R 1$ stage would cause complete crop failure because of initial flower abortion and delayed new flower formation until the end of the growing season, when nontreated plants begin to senesce.

At Thompson, visible symptomology of the medium and high doses of dicamba alone and in combination with glyphosate caused distinguishable injury compared with the nontreated at 20 DAT with the high dose of dicamba alone or combined with glyphosate causing greater than $50 \%$ crop injury (Table 2 ). The nontreated yield was lower than dry edible bean plots receiving the low and medium doses of dicamba alone, the low dose of glyphosate alone, and the combination of the medium doses of dicamba+glyphosate. It was unclear if this result was partially due to the stimulatory effects of these herbicides at very low doses along with the stem breakage of nontreated plants from a high wind storm 3 weeks after the herbicide applications or if the stem breakage alone by the taller nontreated plants was responsible for the yield results. Only plants receiving the high dose of dicamba with or without glyphosate had yield lower than the nontreated.

Yield decline was associated with the increase in observed injury 20 DAT at 


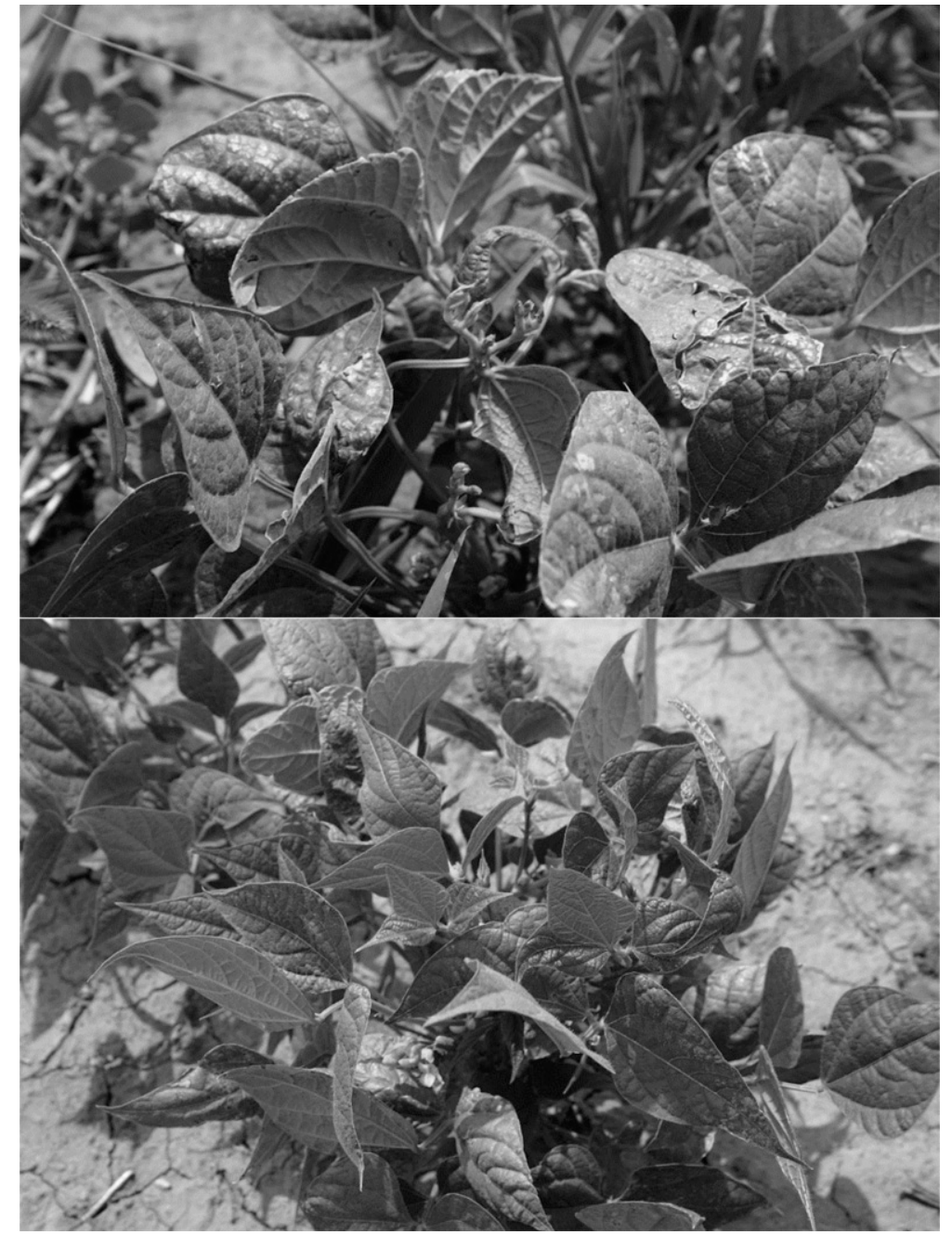

Fig. 3. Dry edible bean visible injury (50\%) $20 \mathrm{~d}$ after treatment from dicamba applied at $0.016 \mathrm{lb} /$ acre $\left(0.0179 \mathrm{~kg} \cdot \mathrm{ha}^{-1}\right)$ above and a nontreated dry edible bean plant below.

both locations. Observed injury increases at Carrington and Thompson resulted in yield reductions of $33.4(P<0.01)$ and $22.6 \mathrm{lb} /$ acre $(P<0.01)$, respectively. Nonsignificance between the herbicide and injury for each location $(P=0.8$ and 0.3$)$ suggested that injury observed from each herbicide resulted in similar yield reductions.

PотAто. At Inkster, all plants that received a sublethal herbicide dose, with the exception of the low and medium doses of glyphosate, had visible injury symptomology (tight cupping of leaves at the growing points) greater than the nontreated at 20 DAT (Table 3 ). However, even with a 25 -fold increase in dose, from low to high, the visible injury from dicamba alone did not differ among rates and was $<20 \%$. Total and marketable yields did not differ among treatments at Inkster, coinciding with the low observed visible injury 20 DAT.

At Oakes, all plants receiving a sublethal herbicide dose, with the exception of the low and medium dose of glyphosate, had visible injury symptomology greater than the nontreated at 20 DAT (Table 3 ). However, injury symptomology was at least twice of what was observed at the Inkster site (Fig. 4). Plants receiving the high dose of glyphosate had injury symptoms (growing point chlorosis) greater than the nontreated, but plants that received a dicamba dose had injury symptoms greater than what was observed on plants that received the high dose of glyphosate. At this location, total yields were reduced only when plants received the highest dose of dicamba or dicamba combined with glyphosate. The effect on marketable yield largely mimicked that of total yield with no marketable yield effect from doses of glyphosate alone and less marketable tubers when plants received the high dicamba dose compared with the nontreated. However, plants receiving the high dose of dicamba or dicamba+glyphosate had a $20 \%$ and $24 \%$ total yield reduction, respectively, compared with the nontreated, although marketable yields were $47 \%$ and $58 \%$ lower, respectively, suggesting that there will be greater economic consequences than total yield reduction if off-target injury occurs.

The relationship between visible symptomology at 20 DAT and yield differed based on the herbicide or herbicide combination applied. At Inkster, no well-defined relationship was found between visible symptomology and total yield or marketable yield. By contrast, total yield and marketable yield were generally reduced as observed injury increased at Oakes $(P<0.01$ and $<0.01$, respectively). In addition, total yield was impacted based on the applied herbicide treatment $[P=0.02$ (dicamba, $-4.6 \mathrm{cwt} / \mathrm{acre}$; glyphosate, $3.8 \mathrm{cwt} /$ acre; dicamba+glyphosate, $-4.5 \mathrm{cwt} /$ acre)], and marketable yield was dependent on the applied herbicide treatment $[P<0.05$ (dicamba, $-6.8 \mathrm{cwt}$ ) acre; glyphosate, $1.7 \mathrm{cwt} / \mathrm{acre}$; and dicamba+glyphosate, $-7.5 \mathrm{cwt} /$ acre)].

\section{Discussion}

Dry edible pea trials had similar responses to herbicide doses except that plants receiving the high dose of dicamba or the medium or high dose of dicamba+glyphosate resulted in reduced pea yield at one of the two locations, which ranged from 16\% to $35 \%$. Al-Khatib and Tamhane (1999) reported that a rate as low as $1.56 \mathrm{~g} \cdot \mathrm{ha}^{-1}(0.022 \mathrm{oz} / \mathrm{acre})$ dicamba would cause observable symptoms, but that the herbicide rate would have to be increased to 25 or $50 \mathrm{~g} \cdot \mathrm{ha}^{-1}$ $(0.36$ or $0.71 \mathrm{oz} /$ acre $)$ to reduce dry edible pea yield by $25 \%$. They also suggested that greater susceptibility of pea plants to dicamba was due to higher herbicide absorption and translocation because of higher air temperature at the time of application. Weather data recorded at each location indicated that air temperature 
Table 2. Impact of sublethal doses of dicamba, glyphosate, or dicamba + glyphosate on dry edible bean foliar injury $20 \mathrm{~d}$ after treatment (DAT) and yield.

\begin{tabular}{|c|c|c|c|c|c|}
\hline \multicolumn{2}{|c|}{ Herbicide dose } & \multicolumn{2}{|c|}{ Carrington, ND } & \multicolumn{2}{|c|}{ Thompson, ND } \\
\hline Dicamba (lb/acre $)^{\mathrm{z}}$ & Glyphosate (lb/acre) & Injury 20 DAT (\%) & Yield (lb/acre) & Injury 20 DAT (\%) & Yield (lb/acre) \\
\hline 0 & 0 & $0 \mathrm{a}^{\mathrm{y}}$ & $1,244 \mathrm{a}$ & $1 \mathrm{a}$ & $1,054 \mathrm{c}$ \\
\hline 0.0004 & 0 & $8 \mathrm{ab}$ & $933 \mathrm{~b}$ & & \\
\hline 0.002 & 0 & & & $9 \mathrm{c}$ & $1,655 \mathrm{ab}$ \\
\hline 0.004 & 0 & $22 \mathrm{bc}$ & $0 \mathrm{~d}$ & & \\
\hline 0 & 0.0003 & & & $3 \mathrm{ab}$ & $1,634 \mathrm{ab}$ \\
\hline 0 & 0.0006 & $2 a$ & $1,246 a$ & & \\
\hline 0 & 0.003 & & & $1 \mathrm{a}$ & $1,143 \mathrm{bc}$ \\
\hline 0 & 0.009 & $17 \mathrm{~b}$ & $374 \mathrm{c}$ & & \\
\hline 0 & 0.03 & & & $0 \mathrm{a}$ & $1,441 \mathrm{abc}$ \\
\hline 0.004 & 0.009 & $32 \mathrm{~cd}$ & $0 \mathrm{~d}$ & & \\
\hline 0.016 & 0.03 & & & $53 \mathrm{~d}$ & $346 \mathrm{~d}$ \\
\hline 0.04 & 0.09 & $42 \mathrm{~d}$ & $0 \mathrm{~d}$ & & \\
\hline
\end{tabular}

${ }^{\mathrm{z}} 1 \mathrm{lb} / \mathrm{acre}=1.1209 \mathrm{~kg} \cdot \mathrm{ha}^{-1}$.

${ }^{\mathrm{y}}$ Within columns, mean followed by the same letter do not differ according to pairwise $t$ tests at $P \leq 0.05$.

Table 3. The effect of sublethal doses of dicamba, glyphosate, or dicamba + glyphosate on potato foliar injury $20 \mathrm{~d}$ after treatment (DAT) and yield.

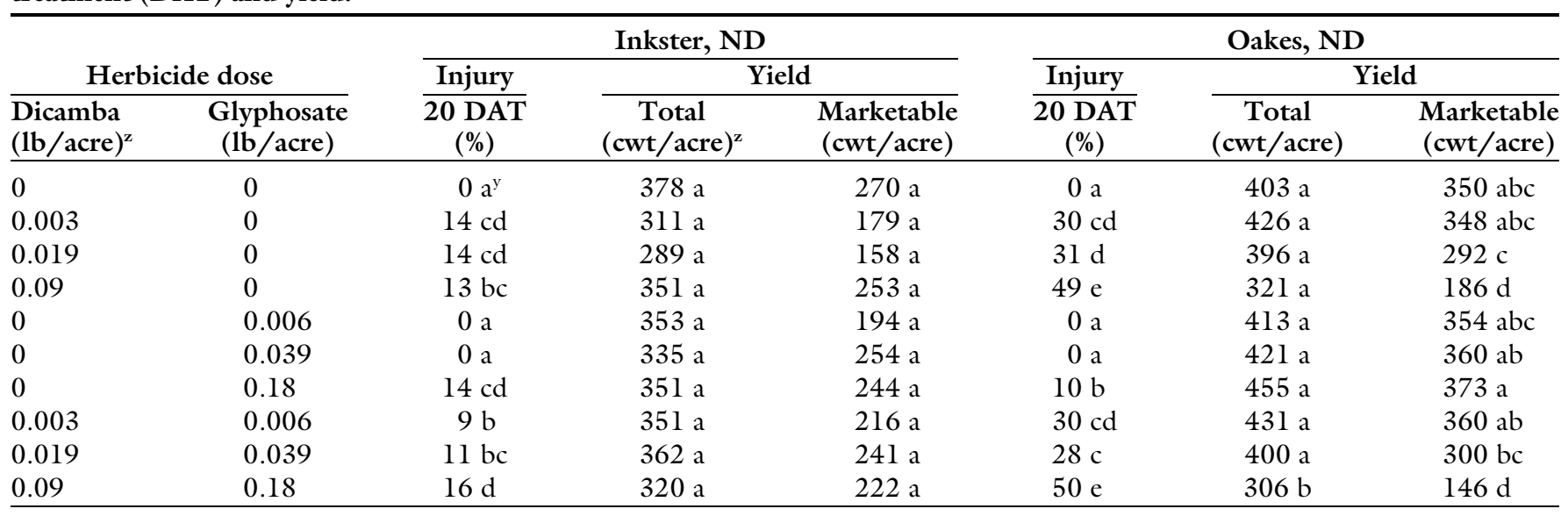

${ }^{\mathrm{z}} 1 \mathrm{lb} /$ acre $=1.1209 \mathrm{~kg} \cdot \mathrm{ha}^{-1}, \mathrm{l} \mathrm{cwt} / \mathrm{acre}=112.0851 \mathrm{~kg} \cdot \mathrm{ha}^{-1}$.

'Within columns, mean followed by the same letter do not differ according to pairwise $t$ tests at $P \leq 0.05$.

when the herbicides were applied was higher at Minot compared with Carrington (Fig. 5). Thus, the yield reduction differences between the two locations may have resulted from higher air temperature at the time of application.

Dry edible bean was more sensitive to dicamba than glyphosate. At Carrington, increasing dicamba and glyphosate doses delayed bean maturation, with harvest occurring between 24 Sept. and 20 Oct. Delayed maturation occurred at Thompson and was severe enough to require chemical desiccation to enable harvest. Similarly, Colquhoun et al. (2014) reported that snap bean was more sensitive to dicamba than $2,4-\mathrm{D}$ or glyphosate. They also reported yield reduction differences between the 2 years of the study, but did not speculate on the cause for this difference. Differences in the doses used for the two locations make comparisons or conclusions difficult. However, both the dry edible pea and the dry edible bean trials were conducted at the Carrington Research Extension Center and showed that the dicamba dose of $0.07 \mathrm{oz} /$ acre eliminated the dry edible bean yield, whereas a dicamba dose of $0.25 \mathrm{oz} /$ acre caused no yield reduction in dry edible pea.

Visible potato injury from sublethal herbicide doses and the coinciding yield responses varied drastically between locations. Several rainfall events at Inkster delayed planting by $\approx 30 \mathrm{~d}$ and may have contributed to the low treatment response at this location. Mortazavi-bak and Raminpour (2009) reported that warm temperatures $\left(\approx 25^{\circ} \mathrm{C}\right.$ and above $)$ do not coincide with potato plant growth, 


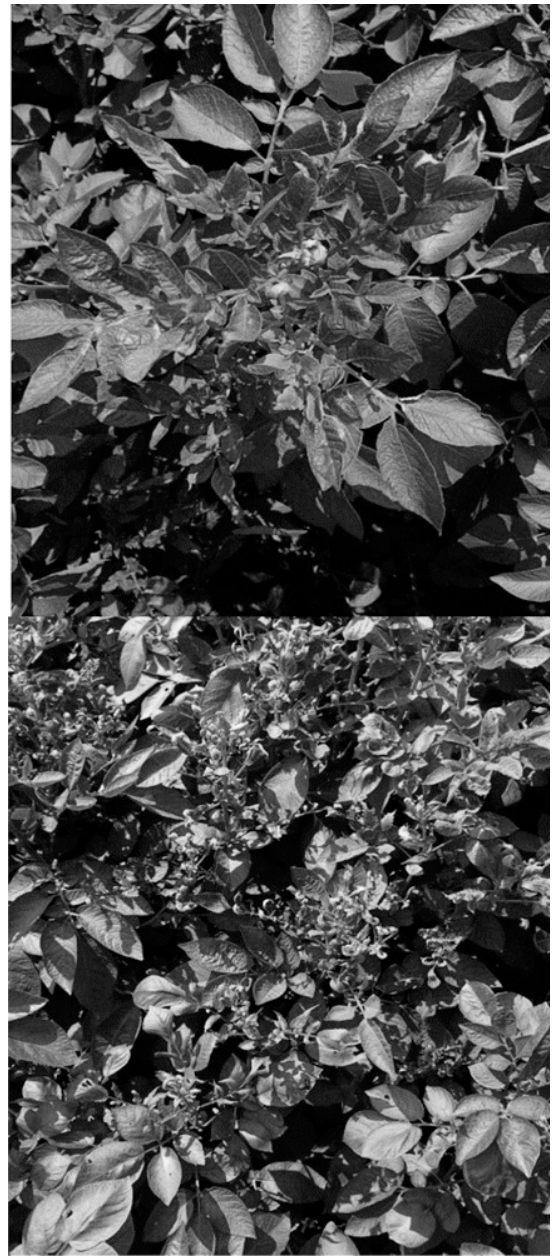

Fig. 4. Potato visible injury (10\%) $20 \mathrm{~d}$ after treatment (DAT) from glyphosate applied at $0.09 \mathrm{lb} /$ acre above and visible injury (30\%) 20 DAT from dicamba applied at $0.019 \mathrm{lb} /$ acre below; $1 \mathrm{lb} /$ acre $=1.1209 \mathrm{~kg} \cdot \mathrm{ha}^{-1}$.

tuber formation, and tuber growth. Air temperatures when herbicide applications were made were higher at Inkster and most likely contributed to the response differences (Fig. 6). However, instead of higher air temperatures increasing the observed injury and reducing the yield as observed in dry edible pea, the opposite response occurred. HattermanValenti (2012) reported a 9-fold yield difference from the same sublethal glyphosate dose to potato and attributed the difference to plant stress from the higher air temperatures just prior and during the herbicide application. Dicamba caused greater marketable yield reduction at Oakes than total yield reduction. Similar results were reported by Wall (1994) where dicamba at $22.2 \mathrm{~g} \cdot \mathrm{ha}^{-1}$ $(0.32 \mathrm{oz} /$ acre $)$ reduced total tuber

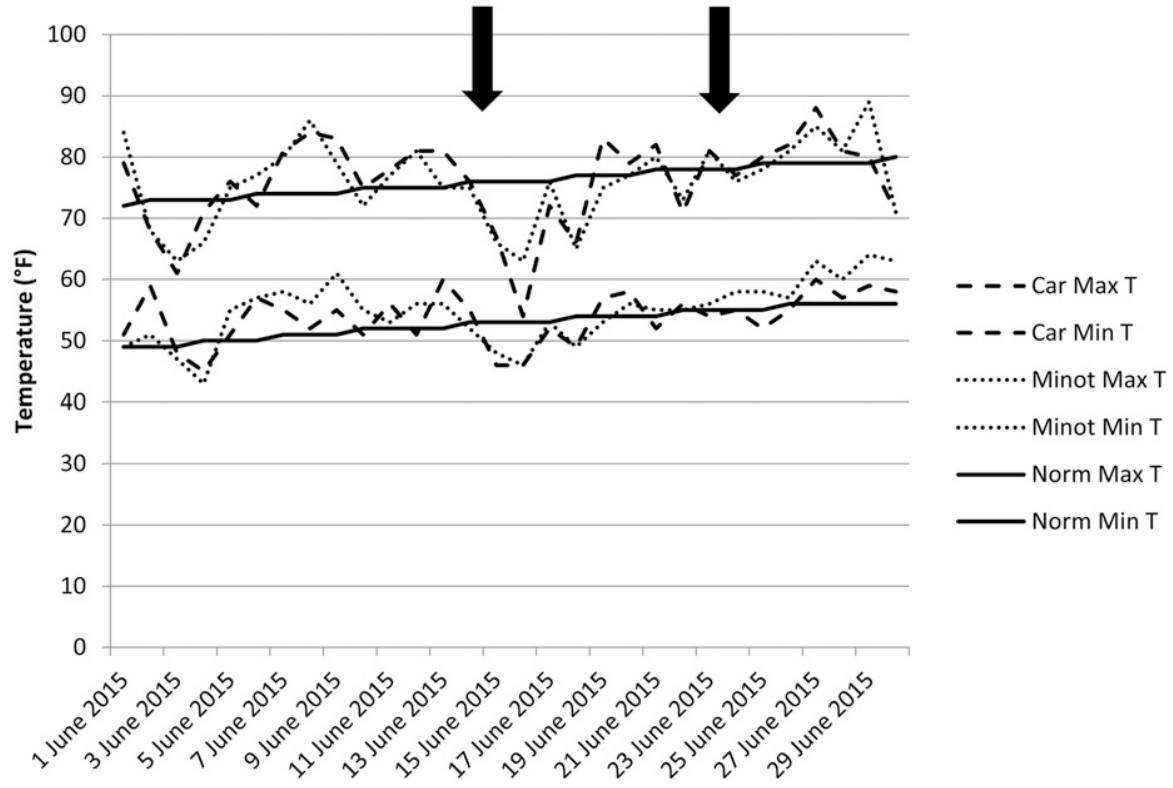

Fig. 5. Minimum air temperature (Min $T)$, maximum air temperature $(\operatorname{Max} T)$, and 30 -year average minimum and maximum air temperatures (Norm Min $T$ and Norm Max T) from weather stations near Carrington, ND (Car), and Minot, ND (Minot), for the month of June with the arrows signifying the day sublethal herbicide doses were applied to dry edible pea; $\left({ }^{\circ} \mathrm{F}-32\right) \div 1.8={ }^{\circ} \mathrm{C}$.

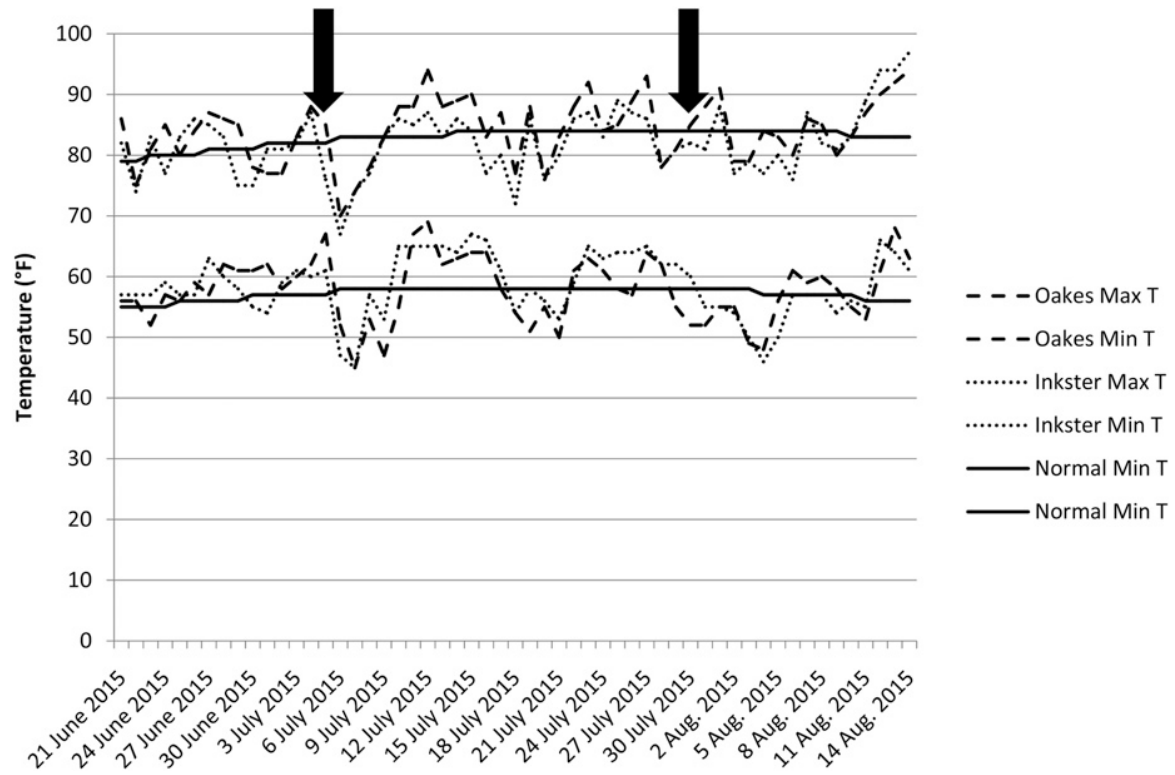

Fig. 6. Minimum air temperature (Min $T)$, maximum air temperature $(\operatorname{Max} T)$, and 30-year average minimum and maximum air temperatures (Normal Min $T$ and Normal Max T) from weather stations near Oakes, ND (Oakes), and Inkster, ND (Inkster), for the months of June, July, and August with the arrows signifying the day sublethal herbicide doses were applied to potato; $\left({ }^{\circ} \mathrm{F}-32\right) \div 1.8={ }^{\circ} \mathrm{C}$.

yield by $40 \%$ and reduced marketable yield by $74 \%$. The $20 \%$ and $24 \%$ total yield reduction at Oakes when plants received the high dose of dicamba or dicamba+glyphosate, respectively, compared with the nontreated, suggested that potato was less sensitive to dicamba than dry edible bean and similar to dry edible pea. The $17 \%$ marketable yield reduction compared with nontreated when plants received $0.32 \mathrm{oz} /$ acre dicamba also suggested that potato and dry edible pea respond similarly to sublethal dicamba dose when applied at the timings used in the current study. 


\section{Conclusions}

Applications of dicamba were found to be more damaging compared with glyphosate, even when applied at relatively low doses. Glyphosate injury (growing point chlorosis) was more difficult to visibly diagnose; however, yield losses were also minimal at these doses. Dicamba visible injury (necrosis of growing points, petiole epinasty, leaf cupping at the growing points, and leaf margin necrosis) was easier to identify, but ratings at 20 DAT generally did not correlate with yield reductions when compared with the nontreated. Synthesis of these six studies on three important horticultural broadleaf crops to North Dakota suggested that drift from dicamba or dicamba+ glyphosate should have a greater impact on yield than glyphosate alone. Dry edible bean was most sensitive to sublethal doses of dicamba, followed by dry edible pea and potato. Environmental conditions during herbicide applications may influence the extent of visible injury and yield reduction to off-target broadleaf crops in response to dicamba or dicamba+ glyphosate drift, but will not eliminate visible injury symptomology. These results show the need for diligence in the application of these herbicides in proximity to susceptible crops and the need to thoroughly clean sprayers before spraying a sensitive crop.

\section{Literature cited}

Al-Khatib, K. and A. Tamhane. 1999. Dry pea (Pisum sativum L.) response to low rates of selected foliar- and soil-applied sulfonylurea and growth regulator herbicides. Weed Technol. 13:753-758.

Bissonnette, H.L., D.A. Preston, and H.A. Lamey. 1993. Potato production and pest management in North Dakota and Minnesota. North Dakota State Univ. Ext. Serv., Ext. Bul. Issue 26.

Colquhoun, J.B., D.J. Heider, and R.A. Rittmeyer. 2014. Relationship between visual injury from synthetic auxin and glyphosate herbicides and snap bean and potato yield. Weed Technol. 24:671-678

Dittmar, P.J., J.A. Ferrell, J.V. Fernandez, and H. Smith. 2016. Effect of glyphosate and dicamba drift timing and rates in bell pepper and yellow squash. Weed Technol. $30: 217-223$.

Endres, G., S. Forster, H. Kandel, J. Pasche, M. Wunsch, J. Knodel, and K. Hellevang. 2016. Field pea production. North Dakota State University Extension Service, Al 166. 28 July 2017. <https:// www.ag.ndsu.edu/publications/crops/ field-pea-production/al l66.pdf>.

Felix, J., R. Boydston, and I.C. Burke. 2011. Potato response to simulated glyphosate drift. Weed Technol. 25:637-644.

Felix, J., R. Boydston, and I.C. Burke. 2012. Response of direct-seeded dry bulb onion to simulated glyphosate drift with variable rate and application timings. Weed Technol. 26:747-756.

Gilreath, J.P., C.A. Chase, and S.J. Locascio. 2001a. Crop injury from sublethal rates of herbicide. I. Tomato. HortScience 36:669-673.

Gilreath, J.P., C.A. Chase, and S.J. Locascio. 2001b. Crop injury from sublethal rates of herbicide. III. Pepper. HortScience 36:677-681.

Hatterman-Valenti, H.M. 2012. Effect of simulated glyphosate drift to four potato processing cultivars. North Central Weed
Sci. Soc. Abstr. 177 (CD-ROM). North Central Weed Sci. Soc., Champaign, IL.

Hatterman-Valenti, H.M. 2014. Simulated glyphosate drift to potato mother plants and effect on daughter tubers used for seed production. Weed Technol. 28:253-258.

Johnson, W.G., S.G. Hallett, T.R. Legleiter, F. Whitford, S.C. Weller, B.P. Bordelon, and B.R. Lerner. 2012. 2,4-Dand dicamba-tolerant crops - Some facts to consider. Purdue Ext. Bul. ID-453-W.

Kruger, G.R., W.G. Johnson, D.J. Doohan, and S.C. Weller. 2012. Dose response of glyphosate and dicamba on tomato (Lycopersicon esculentum) injury. Weed Technol. 26:256-260.

McNaughton, K.E., P.H. Sikkema, and D.E. Robinson. 2012. Response of processing tomato to simulated glyphosate drift followed by in-crop metribuzin application. Weed Technol. 26:757-762.

Mohseni-Moghadam, M. and D. Doohan. 2015. Response of bell pepper and broccoli to simulated drift rates of 2,4-D and dicamba. Weed Technol. 29:226-232.

Mortazavi-bak, A. and R. Ramin-pour. 2009. Effect of planting depth on the performance characteristics of commercial potato varieties. Seed Plant J. 17:106-195.

Orsorno, J., G. Endres, H. Kandel, and D. Bergland. 2013. Dry Bean Production Guide. North Dakota State University Extension Service, Al133. 28 July 2017. <https://www.ag.ndsu.edu/ publications/landing-pages/crops/drybean-production-guide-a-1133>.

U.S. Department of Agriculture. 2017. NASS-Quick Stats database. 27 Jan. 2017. <https://quickstats.nass.usda.gov/>.

Wall, D.A. 1994. Potato (Solanum tuberosum) response to simulated drift of dicamba, clopyralid and tribenuron. Weed Sci. 42:110-114. 